\title{
Pentoxifylline increases cochlear blood flow while decreasing blood pressure in guinea pigs
}

\author{
J.K.M. Coleman ${ }^{1}$, W.S. Quirk ${ }^{2}$, H.A. Dengerink ${ }^{1}$ and J.W. Wright ${ }^{1}$ \\ ${ }^{I}$ Department of Psychology, Washington State University, Pullman, Washington, U.S.A. and ${ }^{2}$ Kresge Hearing Research Institute, \\ University of Michigan, Ann Arbor, Michigan, U.S.A.
}

(Received 20 November 1989; accepted 10 March 1990)

\begin{abstract}
The effects of pentoxifylline on cochlear blood flow (CoBF) were investigated in anesthetized guinea pigs by laser Doppler flowmetry and intravital microscopy red blood cell velocity measurement. Intra-arterial infusion of pentoxifylline (3, 4, and 5 $\mathrm{mg} / \mathrm{kg} / \mathrm{min}$ ) produced dose-dependent reductions in blood pressure, accompanied by significant elevations in CoBF that were not dose-dependent. These results are in general agreement with previous findings from our laboratory utilizing normotensive and spontaneously hypertensive rats, however, in contrast with rats, guinea pigs revealed an initial decrease in CoBF followed by an increase. Also, pentoxifylline produced relatively smaller elevations in CoBF in guinea pigs as compared with those previously reported in rats. Taken together these results support the hypothesis that pentoxifylline increases vascular perfusion by decreasing blood viscosity and increasing the plasticity of red blood cells.
\end{abstract}

Cochlear blood flow; Blood pressure; Laser Doppler flowmeter; Intravital microscopy; Pentoxifylline; Guinea pig

\section{Introduction}

Decreases in cochlear blood flow (CoBF) reduce oxygen and nutrient availability and removal of waste products from the inner ear, and have been suggested to contribute to functional pathologies of the inner ear (Axelsson et al., 1983; Dengerink and Wright, 1988; Hawkins, 1971). These otopathologies include noise-induced hearing loss and Meniere's disease (Borg, 1982; Dulan et al., 1987). Since the cochlear vasculature represents the principal route by which medical treatments can be delivered to the cochlea, increased CoBF may facilitate treatment of these otopathologies (Dengerink and Wright, 1988). However, there are problems associated with increasing CoBF via: 1 vaso-constrictive agents such as angiotensin II (Wright et al., 1985) and vasopressin (Osborn et al., 1987) and blood volume expan-

Correspondence to: John W. Wright, Department of Psychology, Washington State University, Pullman, WA 99164 4820, U.S.A. sion agents such as glycerol (Larson et al., 1982a), dextran (Hultcrantz and Nuttall, 1987), and mannitol (Larson et al., 1982b; Quirk et al., in press) given the concomitant increases in blood pressure; 2) vasodilation using compounds such as vincamine (Coleman, unpublished observations) and carbogen (Goodwin et al., 1984; Melnick, 1984) which can promote a hypotensive response; and 3) osmotic agents such as dextran which may produce rebound effects and kidney failure (Hultcrantz and Nuttall, 1987). There is the further problem that increases in $\mathrm{CoBF}$ can prompt local autoregulatory responses that may preclude increased blood flow (Lawrence et al., 1977; Miller and Dengerink, 1988; Quirk et al., 1988a, 1989).

Our laboratory has been investigating various strategies to elevate $\mathrm{CoBF}$ while attempting to avoid, or diminish the above problems. It has been previously noted that increased blood viscosity and red blood cell (RBC) rigidity are closely related to sensorineural hearing impairment (Browning et al., 1986). We reasoned that if an agent could be found that decreased blood viscosity while having minimal effects on vasodilation, 
blood osmolarity and pressure, its use for increasing CoBF may be superior to the presently available compounds. Pentoxifylline appears to be such a compound. This rheologic agent increases $\mathrm{CoBF}$ without elevating blood pressure, presumably by altering $\mathrm{RBC}$ membrane flexibility, thus promoting erythrocyte penetration into microcapillaries less than one-half their diameter (Antignani et al., 1987; Ehrly, 1976; Manrique and Manrique, 1987). This improved circulation has been used to inhibit ischemic attacks and increase blood flow in patients suffering from peripheral artery disease (Smith et al., 1986).

A recent report from our laboratory utilizing rats (Quirk et al., 1988b) indicated that pentoxifylline decreased blood pressure in a dose-related fashion while facilitating CoBF. However, the guinea pig's low baselevel blood pressure prompts the question as to whether pentoxifylline will be as effective in this species. We have previously reported that larger doses of angiotensin II were required to produce equivalent elevations in $\mathrm{CoBF}$ in the guinea pig as compared with the laboratory rat, while $\mathrm{CoBF}$ was more closely correlated with blood pressure in the guinea pig than the rat (Flynn et al., 1989). A second question concerns the validity of $\mathrm{CoBF}$ measurements using the laser Doppler flowmeter technique (Nuttall, 1988). Therefore, in the present investigation we compared the influence of pentoxifylline upon $\mathrm{CoBF}$ in the guinea pig utilizing the laser Doppler flowmetry and intravital microscopy techniques.

\section{Materials and Methods}

\section{Animals and maintenance}

Male adult guinea pigs (Hartley strain) 120 to 150 days of age, weighing from $400-600 \mathrm{~g}$, were derived from stock obtained from Simonsen Laboratories (Gilroy, CA) and were housed in an AAALAC approved vivarium on a 12:12 $\mathrm{h}$ light : dark cycle initiated at $0700 \mathrm{~h}$, with food and water available ad libitum. All animals in this study were utilized in strict accordance with NIH guidelines for animal research.

\section{Surgical and treatment protocol}

Twenty-four animals were randomly assigned to 1 of 3 groups ( 8 animals each), and anesthetized with Ketamine Hydrocholide (100 mg/kg, Bristol-Myers, Inc.) and Rompun ( $2 \mathrm{mg} / \mathrm{kg}$, Haver Inc.). Each animal was prepared with a flowthrough catheter of the right carotid artery (PE 60, Clay Adams) designed to allow infusion and continuous recording of blood pressure. Details of this surgical procedure have been described elsewhere (Quirk et al.. 1989). The left bulla was exposed and opened for access to the cochlea using a ventral approach. The needle probe $(0.9$ mm o.d.) of the laser Doppler (Advanced Optokinetics Corporation, Model 2100) was placed on the basal turn of the cochlea via a micromanipulator as described by Goodwin et al. (1984). Blood pressure was monitored using a Statham transducer (Model P23AC) and a Grass Instruments polygraph (Model-5D). Baselevel CoBF and blood pressure were monitored for at least $10 \mathrm{~min}$ or until stable. Once baselevel measures of CoBF and systemic blood pressure were achieved, an intraarterial infusion of $0.15 \mathrm{M} \mathrm{NaCl}(50 \mu \mathrm{l} / \mathrm{min})$ was initiated, followed by one dose of pentoxifylline (Sigma, P-1784: 3,4 , or $5 \mathrm{mg} / \mathrm{kg} / \mathrm{min}$ in a volume of $50 \mathrm{ul} / \mathrm{min}$ of $0.15 \mathrm{M} \mathrm{NaCl}$, Travenol 2F7124) titrated to a $\mathrm{pH}$ of 7.0-7.2. Thus, the animals of each group received a control infusion $(0.15 \mathrm{M}$ $\mathrm{NaCl}$ ) and one of the doses of pentoxifylline with $10 \mathrm{~min}$ between the control infusion and the pentoxifylline dose or until baselevel measures were regained. The infusions were counter-balanced with 4 guinea pigs of each group receiving pentoxifylline first and 4 guinea pigs receiving saline first. Blood pressure and CoBF were recorded continuously throughout the baselevel period and subsequent $10 \mathrm{~min}$ infusion periods. For statistical purposes only 8 treatments with $0.15 \mathrm{M} \mathrm{NaCl}$ were randomly selected from the 24 total runs, and the systemic blood pressure and CoBF changes induced by this control treatment were compared against the effects of the three doses of pentoxifylline.

Three additional guinea pigs were anesthetized as described above and were prepared for measurement of $\mathrm{RBC}$ velocity using the intravital microscopy technique as developed by Nuttall (1987a). Again the bulla was cxposed for access to the cochlea. A rectangular portion of bone (approximately $0.2 \times 0.3 \mathrm{~mm}$ ) was scored by knife blade and removed to expose the stria vascularis 
vessels in the second turn of the cochlea. These capillaries were monitored by a fluorescence video monitor with a magnification of approximately $1000 \times$.

To provide fluorescence of the plasma and thereby the exposed capillary network, $0.05 \mathrm{ml}$ of FITC-dextran (MW $=150 \mathrm{kDa}$; $5 \%$ solution by weight in $0.15 \mathrm{M} \mathrm{NaCl}$ ) was intra-arterially infused (Nuttall, 1987a,b). A tracking velocity corrclator (RBC Velocity Tracking Correlator, Model 102, Instrumentation for Physiology and Medicine, Inc., San Diego, CA) which utilizes photometric signals derived from detectors sensitive to light scintillation or modulation due to moving particles, was used for determining $\mathrm{RBC}$ velocity. These RBC velocities were measured before, during, and after the intra-arterial infusion of $0.15 \mathrm{M}$ $\mathrm{NaCl}(50 \mu \mathrm{l} / \mathrm{min}$ for $10 \mathrm{~min})$ and pentoxifylline $(7.5 \mathrm{mg} / \mathrm{kg} / \mathrm{min}$ for $10 \mathrm{~min}$ ).

\section{Statistical analyses}

For those animals utilized in the laser Doppler flowmetry experiment, baselevel blood pressures prior to treatment were compared by a one-way analysis of variance (ANOVA). Maximum changes in blood pressure from baselevel were scored at 30 $s$ intervals throughout each $10 \mathrm{~min}$ infusion period for each animal. This blood pressure data set was submitted to a 4 (groups) $\times 2$ (doses) ANOVA with repeated measures on the second factor. The CoBF measures were scored as a percent of baselevel, and because they did not meet the assumptions of the ANOVA they were submitted to Chi-square non-parametric analysis. Significant effects were further evaluated by Newman-Keuls post-hoc tests with the level of significance set at $P<0.01$.

The blood pressure and CoBF changes measured prior to, and during, the infusion of pentoxifylline using the intravital microscopy technique were evaluated using $t$-tests for related measures.

\section{Results}

There were no significant differences in pre-infusion anesthetized baselevel blood pressure among the treatment groups utilized for determination of CoBF by laser Doppler flowmetry.
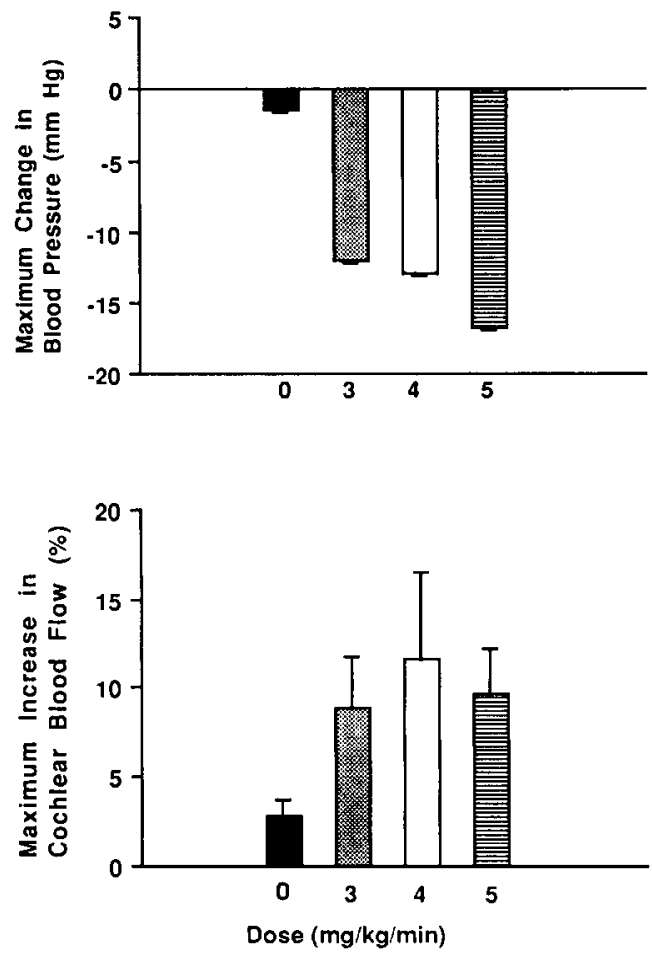

Fig. 1. Maximum changes in blood pressure (upper panel) and cochlear blood flow (lower panel) from baselevel induced by 10 min infusions of $0,3,4$, and $5 \mathrm{mg} / \mathrm{kg} / \mathrm{min}$ doses of pentoxifylline. The mean $( \pm$ SEM) blood pressure baselevel before infusion was $52.3( \pm 1.3) \mathrm{mm} \mathrm{Hg}$. The maximum decreases in blood pressure were $11.9( \pm 0.3), 12.9( \pm 0.2)$ and $16.4( \pm 0.2)$ $\mathrm{mm} \mathrm{Hg}$ for the 3,4 , and $5 \mathrm{mg} / \mathrm{kg}$ doses, respectively. The maximum elevations in CoBF were $8.9( \pm 2.9), 11.6( \pm 4.9)$, and $9.7( \pm 2.5) \%$ for the 3,4 , and $5 \mathrm{mg} / \mathrm{kg}$ doses, respectively.

The overall mean ( \pm SEM) baselevel blood pressure across groups during the pre-infusion period was $52.3( \pm 1.3) \mathrm{mm} \mathrm{Hg}$. Fig. 1 (top panel) presents the maximum change in blood pressure induced by each dose of pentoxifylline. Although the $0.15 \mathrm{M} \mathrm{NaCl}$ infusion yielded minimal effects on blood pressure, significant decreases were observed following the infusion of the 3,4 , and 5 $\mathrm{mg} / \mathrm{kg} / \mathrm{min}$ doses of pentoxifylline, and these decreases followed a dose-response pattern: 11.9 $( \pm 0.3), 12.9( \pm 0.1)$, and $16.4( \pm 0.2) \mathrm{mm} \mathrm{Hg}$, respectively $(F=18.28, \quad$ df $=3,28, \quad P<0.001)$. Post-hoc analyses indicated that each dose was significantly different from the next. These decreases in blood pressure represented percent decrements from baselevel of $22.8,24.7$, and $31.4 \%$, respectively. 

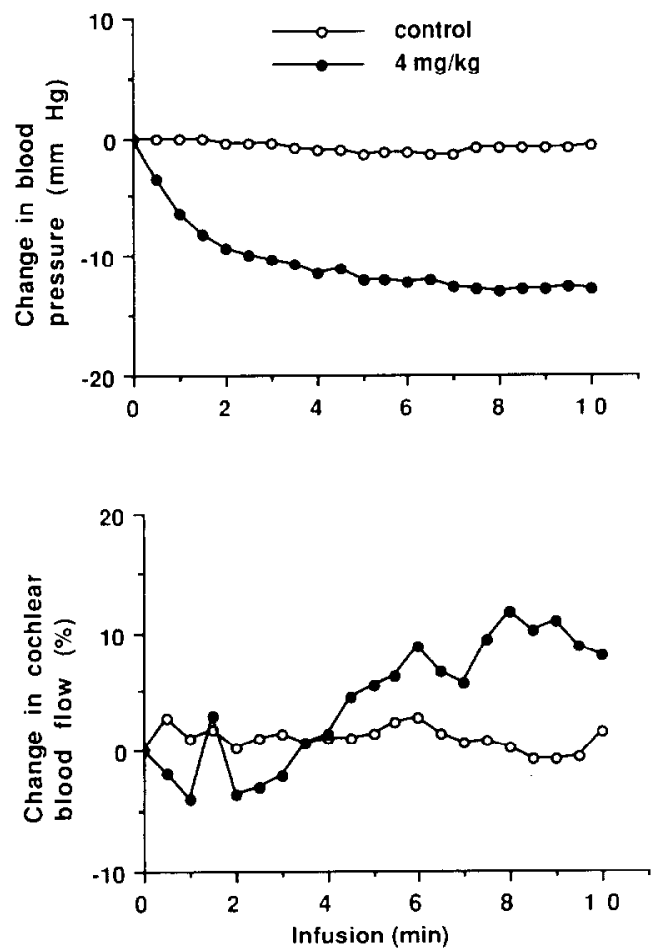

Fig. 2. Mean changes in blood pressure (upper panel)- and cochlear blood flow (lower panel) during infusion of $0.15 \mathrm{M}$ $\mathrm{NaCl}$ or the $4 \mathrm{mg} / \mathrm{kg} / \mathrm{min}$ dose of pentoxifylline. The mean decrease in blood pressure during pentoxifylline infusion was $12.9 \mathrm{~mm} \mathrm{Hg}$, while the maximum increase in CoBF above baselevel was $12.1 \%$. The $4 \mathrm{mg} / \mathrm{kg} / \mathrm{min}$ dose of pentoxifylline is representative of the 3 and $5 \mathrm{mg} / \mathrm{kg} / \mathrm{min}$ doses.

Fig. 1 (bottom panel) displays the maximum changes in $\mathrm{CoBF}$ for each dose of pentoxifylline. Chi-square analysis indicated that these elevations in CoBF were significantly different from baselevel. Specifically, the doses 3,4 , and $5 \mathrm{mg} / \mathrm{kg} / \mathrm{min}$ of pentoxifylline resulted in maximum elevations of $9.9( \pm 2.1), 12.1( \pm 4.7)$, and $9.7( \pm 2.5) \%$, respectively. Chi-square analysis for the 3,4 , and 5 $\mathrm{mg} / \mathrm{kg}$ doses yielded $\chi^{2}=14.75,14.75$, and 24.75 respectively, $P<0.001$. Fig. 2 presents the patterns of changes in blood pressure (top panel) and CoBF (bottom panel) for the $4 \mathrm{mg} / \mathrm{kg}$ dose of pentoxifylline which is representative of the other two doses. During the infusion there was a decrease in blood pressure accompanied by an initial decrease in CoBF followed by a gradual continuous increase during the remainder of the infusion period.
There was also a significant decrease in systemic blood pressure during pentoxifylline infusion $(7.5 \mathrm{mg} / \mathrm{kg} / \mathrm{min}$ ) evidenced by those animals used for intravital microscopy analysis $(t=6.25$, $P<0.001)$. This decrease was from a mean $( \pm \mathrm{SD})$ baselevel of $58( \pm 2.1)$ to $51( \pm 3.4) \mathrm{mm} \mathrm{Hg}$. And there was a concomitant significant elevation in RBC velocity in the stria vascularis vessels in these animals, from $227.7( \pm 17.9)$ to $248.3( \pm 22.7)$ $\mu \mathrm{m} / \mathrm{s} \quad(t=2.49, \quad P<0.05)$. During the $10 \mathrm{~min}$ post-infusion recovery period, systemic blood pressure recovered to baselevel while $\mathrm{RBC}$ velocity remained elevated at $255.5( \pm 23.6) \mu \mathrm{m} / \mathrm{s}$.

\section{Discussion}

The results of this investigation indicate that pentoxifylline increases cochlear blood flow in guinea pigs as previously reported for the laboratory rat (Quirk et al., 1988b). These elevations in CoBF occurred despite significant decreases in systemic blood pressure that appear to be attributable to the rheological effects of pentoxifylline rather than any vasodilative effects (Ehrly, 1976; Smith, 1986). Although the present results from guinea pigs generally agree with the previous findings in rats (Quirk et al., 1988a) there were differences. In contrast with rats there was an initial decrease in CoBF during the infusion of the 3 and $4 \mathrm{mg} / \mathrm{kg} / \mathrm{min}$ doses followed by increases that did not follow a dose response pattern as seen in rats. Also in guinea pigs higher doses of pentoxifylline were required for effect and resulted in smaller reductions in absolute blood pressure than were observed in rats (Quirk et al., 1988a), although the average percent decrements in blood pressure from baselevel were greater in guinea pigs than rats. Specifically, the maximum percent decrements in blood pressure from baselevel for rats were $10.2,17.2$, and $21.6 \%$, at the $1.5,2$, and 3 $\mathrm{mg} / \mathrm{kg}$ doses, respectively; while in guinea pigs these decrements were $22.8,24.7$, and $31.4 \%$ at doses of 3,4 , and $5 \mathrm{mg} / \mathrm{kg}$, respectively. The most effective dose of pentoxifylline in those guinea pigs used for laser Doppler analysis was $4 \mathrm{mg} / \mathrm{kg}$ which promoted blood pressure decreases of approximately $13 \mathrm{~mm} \mathrm{Hg}$, and $\mathrm{CoBF}$ increases of approximately $12 \%$ above baselevel. Although the $5 \mathrm{mg} / \mathrm{kg}$ dose did not follow a dose-response 
pattern it illustrates the effectiveness of pentoxifylline in elevating cochlear blood flow despite a blood pressure decrease of nearly $16.4 \mathrm{~mm} \mathrm{Hg}$ (31.4\% from baselevel). The increase in CoBF persisted beyond the period of infusion.

The intravital microscopy results generally agree with those derived from laser Doppler flowmetry in that systemic blood pressure decreased during the infusion of pentoxifylline, while cochlear red blood cell velocity was elevated. It should be noted that a higher dose of pentoxifylline was employed in the animals used for intravital microscopy measurements, and this dose yielded a 7 $\mathrm{mm} \mathrm{Hg}$ decrease in systemic blood pressure from baselevel, while the decreases noted in the animals used for laser Doppler analysis ranged from 11.9 to $16.4 \mathrm{~mm} \mathrm{Hg}$. At present we have no ready explanation for this discrepancy. It is conceivable that this dampening of effect is due to differences in the amount of anesthetic given to these two groups of animals. Specifically, because intravital microscopy is more sensitive to animal movements than the laser Doppler flowmeter, the intravital microscopy animals may have been inadvertently maintained at a somewhat deeper anesthetic plane. This may have made the animals less responsive to the hypotensive effects of pentoxifylline (Flynn et al., 1988).Histological measures concerned with the impact of noise exposure on the cochlear vasculature generally suggest reduced blood flow with exposure to noise (Axelsson et al., 1981; Axelsson and Dengerink, 1987; Dengerink et al., 1985). These findings have been corroborated with laser Doppler flowmetry (Thorn and Nuttall, 1987) and intravital microscopy (Quirk et al., 1990) studies. Thus, if acoustic trauma results from diminution of blood flow, then pentoxifylline may help to increment blood flow. With respect to basic research, compounds such as pentoxifylline may facilitate our understanding of cochlear blood flow dynamics and thus provide insight into the development of new more effective pharmacological treatments for otopathologies of vascular origin.

\section{Acknowledgements}

This research was supported by grants from the Deafness Research Foundation, NIH NS 11731, and funds provided by Washington State Univer- sity. Special thanks are due to Dr. A.L. Nuttall for his helpful comments on the preparation of this manuscript, and Mrs. Ruth Day for typing the manuscript in final form.

\section{References}

Antignani, P.L., Tododini, A.R., Saliceti, F., Pacino, G. and Bartolo, M. (1987) Results of the clinical, laboratory, and heamorheological investigations of the use of pentoxifylline in high doses. Pharmatherapeutica 5, 50-56.

Axelsson, A. and Dengerink, H.A. (1987) Histological indications of noise effects on the cochlear and red blood cells: A review. Hear. Res. 31, 183-192.

Axelsson, A., Borg, E and Hornstrand, C. (1983) Noise effects on cochlear vasculature in normotensive and spontaneously hypertensive rats. Acta Otolaryngol. 96, 215-225.

Axelsson. A., Vertes, D. and Miller, J. (1981) Immediate noise effects on cochlear vasculature in the guinea pig. Acta Otolaryngol. 91, 237-246.

Borg, E. (1982) Noise induced hearing loss in normotensive and spontaneously hypertensive rats. Hear. Res. 8, 117-130.

Browning, G.G., Gatehouse, S. and Lowe, G.D.O. (1986) Blood viscosity as a factor in sensorineural hearing impairment. Lancet 1, 121-123.

Dengerink, H.A. and Wright, J.W. (1988) Physiology of the ear. In: Jahn, A.F. and Santos-Sacchi, J.(Eds.), Circulation of the Inner Ear. Raven Press, New York, pp. 327-340.

Dengerink, H., Miller, J., Axelsson. A., Vertes, D. and VanDalfsen, P. (1985) The recovery of vascular changes following brief noise exposure. Acta Otolaryngol. 100, 1925.

Dulan, D., Aran, J.M., and Schacht, J. (1987) Osmotically induced motility of the outer hair cells: implications in Meniere's disease. Arch. Oto-Rhino-Laryngol. 244, $104-$ 107.

Ehrly, A. (1976) Improvement of the flow properties of blood: A new therapeutical approach in occlusive arterial disease. Angiology 24 (3), 188-196.

Flynn, A.J., Dengerink, H.A. and Wright, J.W. (1988) Blood pressure in resting, anesthetized and noise-exposed guinea pigs. Hear. Res. 34, 201-206.

Flynn, A.J., Quirk, W.S., Dengerink, H.A. and Wright, J.W. (1989) The effects of intracerebroventricularly administered angiotensin 11 on blood pressure and cochlear blood flow in rats and guinea pigs. Hear. Res. 41, 249-254.

Goodwin, P.W., Miller, J.M., Dengerink, H.A., Wright, J.W. and Axelsson, A. (1984) The laser Doppler: A non-invasive measure of cochlear blood flow. Acta-Oto-Laryngol. (Stockholm) 98, 403-412.

Hawkins, J. (1971) The role of vasoconstriction on noise induced hearing loss. Ann. Otolaryngol. 80, 903-913.

Hulterantz, E. and Nuttall, A.L. (1987) Effect of hemodilation on cochlear blood flow measured by laser Doppler flowmetry. Am. J. Otolaryngol. 8, 10-16.

Larson, H.C., Angelbotg, C. and Hultcrantz, E. (1982a) The effects of urea and mannitol on cochlcar blood flow. Acta Otolaryngol. 94, 249-252. 
Larson, H.C., Angelborg, C., and Hultcrantz, E. (1982b) The effect of glycerol on blood flow. Oto-Rhino-Laryngol. 44, $101-107$.

Lawrence, M., Nuttall, A.L. and Burgio, P.A. (1977) Oxygen reserve and autoregulation in the cochlea. Acta Otolaryngol. 83, 146-152,

Manrique, R.V. and Manrique, V. (1987) Enhancement of the antiaggregatory cffect of prostacyclin by pentoxifylline. Angiology 38 (2 Pt 1), 101-108.

Melnick, W. (1984) Medicinal therapy for hearing loss resulting from noise exposure. Am. J. Otolaryngol. 5, 425-431.

Miller, J.M. and Dengerink, H.A. (1988) Control of inner ear blood flow. Abstr. Assoc. Res. Otolaryngol. Clearwater Beach. Florida.

Nuttall, A.L. (1987a) Techniques for the observation and measurement of red blood cell velocity in vessels of the guinea pig cochlea. Hear. Res. 27, 111-119.

Nuttall, A.L. (1987b) Velocity of red blood cell flow in capillaries of the guinea pig cochlea. Hear. Res. 27, 121-128.

Nuttall, A.L. (1988) Methodological approaches for measurement of cochlear blood flow. Paper Assoc. Res. Otolaryngol. Clearwater Beach, Florida.

Osborn, J.W., Skelton, M.M. and Cowley, A.W. (1987) Hemodynamic effects of vasopressin compared with angiotensin II in conscious rats. Am. J. Physiol. 252, 628-637.

Quirk, W.S., Nuttall, A.L. and Miller, J.M. (1990) Noise-induced changes in red blood cell velocity and vessel diame- ter in the lateral wall of the rat cochlea. Abstr. Assoc. Res. Otolaryngol. Clearwater Beach, Florida.

Quirk, W.S., Dengerink, H.A., Coleman, J.K. and Wright, J.W. (1989) Cochlear blood flow autoregulation in Wistar-Kyoto rats. Hear. Res $41,53,60$

Quirk, W.S., Bademian. M.J., Wright, J.W. and Dengerink. H.A. Effects of mannitol and dextran on cochlear blood flow in normotensive and spontancously hypertensive rats. Acta Otolaryngol. (in press).

Quirk. W.S., Wright, J.W., Dengerink, H.A. and Miller, J.M. (1988a) Angiotensin II Induced changes in cochlear blood flow and blood pressure in normotensive and spontaneously hypertensive rats. Hear. Res. 32, 129-136.

Quirk, W.S., Dengerink, H.A., Bademian, M.J., Hall, K.W., and Wright, J.W. (1988b) The effects of pentoxifylline in normotensive and spontaneously hypertensive rats. Hear. Res, 36, 175-180.

Smith, R.V., Waller, E.S., Dolvisio, J.T. Bauza, M.T. Puris, K.. Ho. I. and Lassman, H.B. (1986) Pharmacokinetics of orally administered pentoxifylline in humans. J. Pharm. Sci. $75.47-52$.

Thorn, P.R. and Nuttall, A.L. (1987) Laser Doppler measure ments of cochlear blood flow during loud sound exposure in the guinea pig. Hear. Res. 27, 1-10.

Wright, J.W., Morseth, S.L.. Abhold, R.H. and Harding, J.W. (1985) Pressor action and dipsogenicity induced by angiotensin $I I$ and III in rats. Am. J. Physiol. 249. R514-R521. 